\title{
Identificación molecular y evaluación de bacterias en el desarrollo vegetativo y producción de chile habanero
}

\author{
Molecular identification and evaluation of bacteria in the vegetative development and production of \\ habanero pepper
}

\begin{abstract}
Jacel Adame-García', Félix David Murillo-Cuevas*, Felipe Roberto Flores-de la Rosa², Víctor Velázquez-Mendoza1, Mario López-Vázquez', Héctor Cabrera-Mireles ${ }^{3}$, Efraín Antonio-Vázquez'

1 Tecnológico Nacional de México/IT Úrsulo Galván. Km 4.5 Carretera Cd. Cardel-Chachalacas, CP. 91667. Úrsulo Galván, Veracruz, México.

2 Instituto Nacional de Investigaciones Forestales, Agrícolas y Pecuarias. CIRGOC, Campo Experimental Ixtacuaco. Carretera Federal Martínez de la Torre-Tlapacoyan, Ver. km 4.5. Congregación Rojo Gómez, Tlapacoyan, Veracruz, CP. 93650, México. 3 Instituto Nacional de Investigaciones Forestales, Agrícolas y Pecuarias, CIRGOC, Campo Experimental Cotaxtla, Carretera Federal Veracruz -Córdoba, km. 34.5. Medellín de Bravo, Veracruz, México. CP. 94992, México.
\end{abstract}

\section{RESUMEN}

La producción de chile habanero se realiza con fertilización química, lo cual contamina el suelo y los mantos acuíferos. Esto ha motivado la búsqueda de alternativas sostenibles como las bacterias promotoras de crecimiento. El objetivo de esta investigación fue aislar bacterias promotoras del crecimiento, identificarlas molecularmente y evaluar sus efectos en el desarrollo vegetativo y producción de chile habanero. Se aislaron e identificaron cinco cepas bacterianas a partir de muestras de distintos usos de suelo; el sistema agroforestal registró en promedio la mayor cantidad $\left(3.5 \times 10^{5}\right.$ UFC $\mathrm{g}^{-1}$ ) de cepas bacterianas. El análisis del gen ADN ribosomal $16 \mathrm{~S}$ indicó que las bacterias se asocian a diferentes especies del género Bacillus, sin embargo, el estudio filogenético demostró que no es posible aún identificarlas a nivel de especie; estas cepas estimularon el crecimiento de las plántulas (6.86, 6.70 y $6.76 \mathrm{~cm}$ respectivamente). En la evaluación en macrotúnel, la cepa EAV2 fue la que estimuló el desarrollo de plantas $(38.63 \mathrm{~cm})$ y mejor peso de frutos $(6.45 \mathrm{~g})$.

Palabras claves: Bacillus, biofertilizantes, hortalizas.

\section{ABSTRACT}

The production of habanero pepper includes the use of chemical fertilization, which contaminates the soil and aquifer mantles. This environmental damage has motivated the search for sustainable alternatives such as growthpromoting bacteria. This research aimed to isolate growthpromoting bacteria, identify them molecularly, and evaluate their effects on the vegetative development and production of habanero pepper. Five bacterial strains were isolated and identified from samples from different land uses; the agroforestry system recorded on average the most significant amount $\left(3.5 \times 10^{5} \mathrm{CFU} \mathrm{g}^{-1}\right)$ of bacterial strains. Analysis of the $16 \mathrm{~S}$ ribosomal DNA gene indicated that the bacteria were associated with species belonging to the Bacillus genus; however, the phylogenetic study shows that the identification at a species level is not possible; these strains stimulated better the seedlings growth $(6.86,6.70$ and $6.76 \mathrm{~cm}$ respectively).
In the macro tunnel greenhouse evaluation, the EAV2 strain best stimulated the development of plants $(38.63 \mathrm{~cm})$ and produced better fruit weight $(6.45 \mathrm{~g})$.

Keywords: Bacillus, biofertilizers, vegetables.

\section{INTRODUCCIÓN}

La producción de hortalizas en México es una de las actividades más importantes en la generación de recursos económicos, además de tener una particular importancia en la agricultura de subsistencia y contribuir en la generación de empleos en el campo (SIAP, 2016). Entre las hortalizas de importancia económica se encuentra el chile habanero (Capsicum chinense Jacq.), el cual tiene una alta demanda en el mercado nacional e internacional debido a su creciente uso en los alimentos, así como por ser fuente de colorantes naturales y compuestos fitoquímicos benéficos para la salud tales como los capsaicinoides (Ruiz-Bello et al., 2016).

La mayor parte de la producción de chile habanero se realiza con fertilización química (Reyes y Cortez, 2017; Ramírez-Vargas et al., 2019), lo que ha generado un uso excesivo de fertilizantes (Grageda-Cabrera et al., 2012). Por otro lado, el uso intensivo de fertilizantes químicos daña el suelo, contaminan el agua y contribuyen significativamente al cambio climático del planeta (Benbi, 2013). Esto ha motivado la búsqueda de alternativas más sostenibles que permitan una nutrición orgánica, que satisfaga las necesidades del productor y conserven el medio ambiente, como el de la agricultura orgánica, la cual utiliza abonos orgánicos (Luna et al., 2016; Reyes-Pérez et al., 2018; Mendivil-Lugo et al., 2020), bioestimulantes (Torres et al., 2016; Arenas-Julio et al., 2021) y microorganismos (Espinosa-Palomeque et al., 2019; Rodríguez-Hernández et al., 2020) para la fertilización de los cultivos.

Una amplia gama de microorganismos que habitan en el suelo son vitales para las plantas, a través de interacciones benéficas que se desarrollan entre estos (Ríos et al., 2016). Existen antecedentes sobre el crecimiento de las plantas y la estimulación del rendimiento mediante microorganismos 
benéficos del suelo (Rodríguez-Hernández et al., 2020). Estos microorganismos desempeñan funciones importantes en el suelo como la fijación biológica de nitrógeno y la solubilización de fosfatos, las cuales son actividades que efectúan mediante enzimas como nitrogenasas y fitasas, con un efecto positivo en la promoción del crecimiento vegetal y en el aumento del potencial productivo (Corrales et al., 2017). Bacterias del género Bacillus promueven el crecimiento vegetal a través de la fijación de nitrógeno y como biofertilizantes son una opción amigable al suelo y al ambiente, que dan respuesta a la necesidad de implementar una agricultura sostenible (Corrales et al., 2017; Rodríguez-Hernández et al., 2020). De tal forma que se considera que existen cepas de bacterias en suelos productivos con capacidad promotora del crecimiento vegetal que pueden ser usados como bioestimulantes o biofertilizantes para cultivos de hortalizas. Por lo que el objetivo de este trabajo fue aislar bacterias promotoras del crecimiento vegetal, identificarlas molecularmente y evaluar sus efectos en el desarrollo vegetativo y producción de chile habanero en condiciones protegidas.

\section{MATERIALES Y MÉTODOS \\ Área de estudio}

El trabajo se realizó en el Tecnológico Nacional de México, campus Úrsulo Galván (ITUG), ubicado en el municipio de Úrsulo Galván, en la región centro costera de Veracruz. El clima de esta región se clasifica como Aw (tropical húmedo-seco) por el sistema Köppen-Geiger, definido como cálido subhúmedo con lluvias en verano, con un rango de temperatura que oscila entre 24 y $26^{\circ} \mathrm{C}$, y un rango de precipitación entre 1100 y 1300 mm (INAP, 2013).

\section{Obtención de bacterias promotoras del crecimiento ve- getal}

Para la obtención de bacterias promotoras del crecimiento vegetal se realizó un muestreo de suelo en los terrenos productivos pertenecientes al ITUG. El muestreo se realizó en la época de lluvias en el mes de agosto, época en la cual se ha registrado mayor abundancia de fauna y microflora edáfica (Murillo-Cuevas et al., 2019). Se tomaron muestras de seis usos de suelo diferentes los cuales fueron: 1) cultivo de limón persa (Citrus latifolia Tan.), con un polígono de muestreo de 2.254 ha; 2) cultivo de caña de azúcar (Saccharum officinarum L.) variedad ATEMEX 96-40, con un polígono de muestreo de $2.03 \mathrm{ha}$; 3) cultivo de lichi (Litchi chinensis Sonn.), con un polígono de muestreo de $1.535 \mathrm{ha}$; 4 ) área con pasto Mombasa (Panicum maximum cv. Mombasa), con un polígono de muestreo de $1.584 \mathrm{ha}$; 5) suelo sin uso agrícola, denominado acahual, con predominancia de las especies $\mathrm{Co}$ cuite (Gliricidia sepium), Nacastle (Enterolobium cyclocarpum), Guácimo (Guazuma ulmifolia), Huizache (Acacia cochliacantha), Capulín (Karwinskia humboldtiana) y Guaje (Lysiloma divaricatum); 6) sistema agroforestal que cuenta con cultivos de Morera (Morus alba), Colorín (Erythrina americana), Bambú (Bambusa vulgaris), Guácimo (Guazuma ulmifolia), Mulato (Bursera simaruba) y Cocuite (Gliricidia sepium). Dentro de cada área de uso de suelo se establecieron dos parcelas de $10 \mathrm{~m}^{2}$, dentro de cada parcela se establecieron dos puntos de muestreo de manera aleatoria, en los cuales se utilizó un cuadrante de $25 \times 25 \mathrm{~cm}$ para determinar el área de la muestra. Las muestras de suelo se tomaron a una profundidad de 0-15 cm, considerada óptima para encontrar mayor abundancia y riqueza de organismos (Franco et al., 2016). Se colectaron un total de cuatro muestras por uso de suelo en dos muestreos.

Para obtener los inóculos se prepararon diluciones (1:9) seriadas $\left(10^{-1}\right.$ a $\left.10^{-6}\right)$ en solución fosfatos $\left(0.25 \mathrm{M} \mathrm{KH}_{2} \mathrm{PO}_{4}\right)$ (NOM-110-SSA-1994), con agitación constante a $120 \mathrm{rpm}$ durante $10 \mathrm{~min}$ en un agitador orbital (Lab Line ${ }^{\circ}$ ). Se tomó un inóculo de $100 \mu \mathrm{L}$ y se dispersaron sobre medio de cultivo ELMARC pH 6.8-7.0 ( $5 \mathrm{~g}$ de manitol, $0.2 \mathrm{~g}$ extracto de levadu$\mathrm{ra}, 0.25 \mathrm{~g} \mathrm{~K}_{2} \mathrm{HPO}_{4^{\prime}} 0.1 \mathrm{~g} \mathrm{MgSO}_{4} 7 \mathrm{H}_{2} \mathrm{O}, 0.05 \mathrm{~g} \mathrm{NaCl}, 1: 400$ rojo de Congo, $18 \mathrm{~g}$ agar por $\mathrm{L}$ de medio). Las cajas se incubaron a $30{ }^{\circ} \mathrm{C}$ durante $24 \mathrm{~h}$. La siembra se realizó por triplicado. Una vez seleccionados los microorganismos se inocularon en medio líquido Winogradsky pH 6.5-7.0 [Sacarosa $10 \mathrm{~g} / \mathrm{L}$, $\mathrm{CaCO}_{3} 0.1 \mathrm{~g} / \mathrm{L}$, Agar $15 \mathrm{~g} / \mathrm{L}, 5 \mathrm{ml}$ Solución mineral $\left(\mathrm{K}_{2} \mathrm{HPO}_{4}\right.$ $50 \mathrm{~g} / \mathrm{L}, \mathrm{MgSO}_{4}{ }^{*} 7 \mathrm{H}_{2} \mathrm{O} 25 \mathrm{~g} / \mathrm{L}, \mathrm{NaCl} 25 \mathrm{~g} / \mathrm{L}, \mathrm{FeSO}_{4}{ }^{*} 7 \mathrm{H} 2 \mathrm{O} 1 \mathrm{~g} / \mathrm{L}$, $\left.\left.\mathrm{NaMoO}_{4}{ }^{*} 2 \mathrm{H}_{2} \mathrm{O} 1 \mathrm{~g} / \mathrm{L}, \mathrm{MnSO}_{4} * 4 \mathrm{H}_{2} \mathrm{O} 1 \mathrm{~g} / \mathrm{L}\right)\right]$ y se incubaron en agitación a $250 \mathrm{rpm}$ durante $76 \mathrm{~h}$.

\section{Identificación molecular de bacterias promotoras del crecimiento vegetal}

La extracción de ADN de bacterias se realizó de acuerdo al método de Giraffa et al. (2000). El gen ADN ribosomal 165 se amplificó con los iniciadores UnivBactF/UnivBactR $\left({ }^{5}\right.$ GATCCTGGCTCAGGATGAAC $\left.{ }^{3}\right) /\left({ }^{\prime}\right.$ GGACTACCAGGGTATCTA$\mathrm{ATC}^{3^{\prime}}$ ) en un volumen de reacción de $25 \mu \mathrm{L}$ ( 1 X PCR buffer, 2.5 $\mathrm{mM} \mathrm{MgCl}, 1$ U Taq DNA pol, $0.20 \mathrm{mM}$ dNTPs, 15 pM de cada iniciador y 50-100 ng de ADN genómico). La amplificación se realizó en un termociclador (Mastercycler) bajo el siguiente programa de ciclos térmicos: una desnaturalización inicial de $2 \mathrm{~min}$ a $94^{\circ} \mathrm{C}, 30$ ciclos de desnaturalización a $94^{\circ} \mathrm{C}$ por $1 \mathrm{~min}$, alineamiento a $55^{\circ} \mathrm{C}$ por 1 min y extensión a $72^{\circ} \mathrm{C}$ por $1 \mathrm{~min}$; seguido de una extensión final a $72^{\circ} \mathrm{C}$ durante $5 \mathrm{~min}$.

Para la secuenciación, se purificaron los productos de PCR con el kit de purificación ChargeSwitch - Pro PCR Clean-up Kit (Invitrogen) de acuerdo a las instrucciones del fabricante. Los fragmentos se secuenciaron en el Instituto de Biotecnología de la UNAM. Todas las secuencias se registraron en el GenBank del National Center for Biotechnology Information (NCBI)con números de accesión (MW015771MW015776).

Los datos de secuencias se analizaron en el GenBank mediante el sistema Basic Local Alignment Search Tool (BLAST). Se obtuvieron las secuencias relacionadas mediante BLAST a las secuencias obtenidas de las cepas evaluadas y se alinearon mediante el algoritmo ClustaIW (gap open =15; gap extend=3) en el software Bioedit, posteriormente se realizó la búsqueda del árbol más parsimonioso mediante algoritmos de búsqueda de nueva tecnología (ratchet+drfit+sectorial search) mediante el software TNT. Se realizó un remuestreo 
mediante Bootstrap con 999 réplicas. Como grupo externo se utilizó una secuencia $16 \mathrm{~S}$ de la bacteria E. coli.

\section{Evaluación de bacterias en la emergencia, desarrollo y producción de chile habanero}

Para la emergencia de plántulas de chile habanero, en charolas con sustrato Peat Moss no estéril, se inocularon con $1 \mathrm{~mL}$ de solución bacteriana $\left(10^{8} \mathrm{UFC} / \mathrm{mL}\right), 100$ semillas de chile habanero variedad Jaguar. Las variables de respuesta fueron porcentaje de emergencia, altura de plántula y peso seco de plántulas $\left(65^{\circ} \mathrm{C}\right.$ durante 72 horas) a los 20 días después de la inoculación (ddi).

Por otra parte, para evaluar el desarrollo y producción de plantas de chile habanero, en estructuras tipo macrotúnel de $3 \times 30 \mathrm{~m}$, forrados con malla antiáfidos y equipado con sistema de riego por goteo, se trasplantaron plántulas en bolsas de $5.5 \mathrm{~L}$ volumen con sustrato turba/vermiculita y composta de cachaza de caña de azúcar no estéril (50:50 v/v). Las plántulas se inocularon ocho días después del trasplante con $10 \mathrm{~mL}$ de solución bacteriana $\left(10^{8} \mathrm{UFC} / \mathrm{mL}\right)$ directamente sobre la raíz. Para la evaluación en plantas de chile habanero las variables fueron altura a los ocho ddi, altura al inicio de la floración y peso del fruto a los $65 \mathrm{ddi}$.

\section{Análisis de datos y diseño experimental}

La evaluación se estableció en un diseño de bloques al azar con cuatro repeticiones por cepa bacteriana, los tratamientos evaluados correspondieron a cada una de las bacterias evaluadas, el testigo consistió en plantas no inoculadas.

Para comparar el efecto de las bacterias promotoras de crecimiento en la emergencia de las plántulas de chile habanero se realizó un análisis no paramétrico de Friedman y para comparar los efectos de las bacterias sobre las variables morfológicas de plántula se realizó un ANOVA y una comparación de medias de Tukey a $=0.05$. Los análisis estadísticos se realizaron con el software Infostat versión 2020.

\section{RESULTADOS Y DISCUSIÓN}

\section{Bacterias promotoras del crecimiento vegetal en diferen-} tes usos de suelo

La abundancia promedio de las cepas bacterianas promotoras de crecimiento en los diferentes usos de suelo fue significativamente diferente. En el suelo del sistema agroforestal se obtuvo en promedio la mayor cantidad de bacterias $\left(3.5 \times 10^{5} \mathrm{UFC}^{-1}\right)$, mientras que el suelo con pasto fue el que registró la menor abundancia $\left(5 \times 10^{4} \mathrm{UFC} \mathrm{g}^{-1}\right)$. El suelo con cultivo de caña de azúcar y limón persa no desarrollaron crecimiento de microorganismos en los medios de cultivo selectivos (Figura 1).

En este caso, Vessey (2003) menciona que las diferencias en cuanto al número de UFC de bacterias de vida libre y su distribución en determinados usos de suelo, están definidos por diversos factores como las características físicas y químicas del suelo, el contenido de materia orgánica, la humedad, la relación carbono nitrógeno y pH, las condiciones climáticas y los exudados de las raíces de las plantas

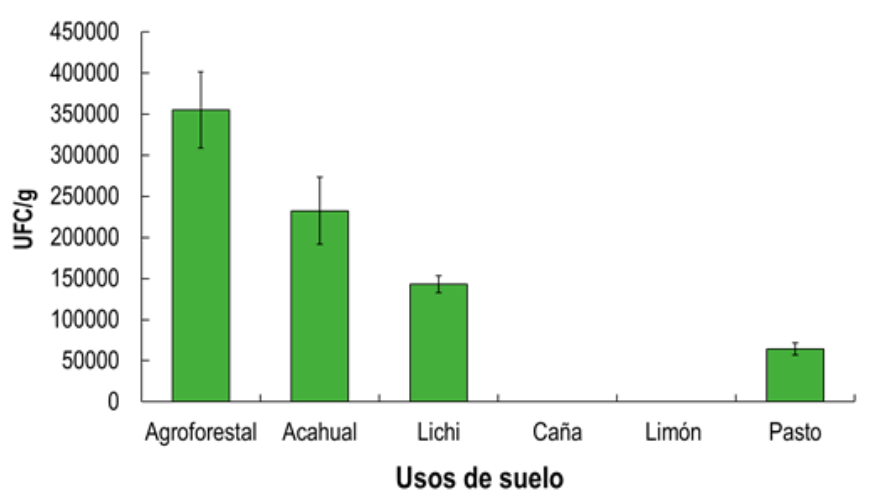

Figura 1. Concentración de bacterias extraídas de suelos con diferente ocupación.

Figure 1. Concentration of bacteria extracted from soils with different occupation.

que sirven de nutrientes para las bacterias; esas condiciones se presentaron en este trabajo al evaluar en diferentes usos de suelo, los cuales cambiaron de acuerdo al cultivo establecido y al manejo proporcionado.

Nuestros resultados, indicaron que los suelos con cultivo de caña de azúcar y limón persa $\left(<10^{1} \mathrm{UFC}^{-1}\right)$ y pasto $\left(5 \times 10^{4} \mathrm{UFC}^{-1}\right)$ fueron los que presentaron menor recuperación de bacterias con respecto al suelo agroforestal

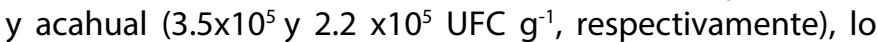
cual era de esperarse ya que son sistemas similares entre sí, con diferencias en comparación con los sistemas tradicionales o intensivos agrícolas (Vallejo-Quintero, 2013). No obstante, nuestros resultados difieren con lo reportado por Mantilla-Paredes et al. (2009), quienes encontraron una mayor recuperación de aislamientos primarios en suelos de pastizal, seguidos por los sitios con mayor riqueza vegetal como bosques; además, reportan alta presencia de bacterias diazótrofas en el interior y en la superficie de las raíces de varias gramíneas tropicales.

Sin embargo, de acuerdo con Paudel et al. (2012) los sistemas agroforestales tienen mayor actividad enzimática y diversidad microbiana en comparación a otros cultivos, debido a diferencias en la cantidad y en la calidad de la materia orgánica y los exudados de las raíces provenientes de los cultivos de cobertura y vegetación permanente. De tal forma que, Kaur et al. (2002) reportaron que los sistemas agroforestales incrementan la biomasa microbiana y su actividad, debido a los efectos positivos ejercidos por la incorporación de árboles y los ingresos de materia orgánica.

\section{Identificación molecular de bacterias promotoras de crecimiento vegetal}

Los resultados de la amplificación del fragmento $16 \mathrm{~S}$ rRNA de los aislamientos evaluados generó un producto de $\sim 800 \mathrm{pb}$ (Figura 2). Los resultados obtenidos del análisis BLAST asociaron al género Bacillus, esto se resume en el Tabla 1.

El género Bacillus pertenece a un grupo de bacterias formadoras de endosporas aeróbicas que abundan en los 
Tabla 1. Resultado de análisis BLAST de las secuencias $16 \mathrm{~S}$ obtenidas de las cepas evaluadas.

Table 1. Results of BLAST analysis of the $16 \mathrm{~S}$ sequences obtained from the evaluated strains.

\begin{tabular}{lccccc}
\hline Cepa & $\begin{array}{c}\text { Especie } \\
\text { asociada }\end{array}$ & $\begin{array}{c}\text { Porcentaje } \\
\text { de cobertura }\end{array}$ & e-value & $\begin{array}{c}\text { Porcentaje } \\
\text { de } \\
\text { Identidad }\end{array}$ & $\begin{array}{c}\text { Número de } \\
\text { Accesión } \\
\text { NCBI }\end{array}$ \\
\hline VVM1 & B. megaterium & $100 \%$ & 0.0 & $97.77 \%$ & MT588737.1 \\
EAV2 & B. megaterium & $99 \%$ & 0.0 & $98.44 \%$ & MT510154.1 \\
JAG3 & B. subtilis & $62 \%$ & $2 \times 10^{-148}$ & $91.35 \%$ & CP035231.1 \\
FDMC4 & B. subtilis & $98 \%$ & 0.0 & $90.88 \%$ & CP035164.1 \\
JVN5 & B. simplex & $99 \%$ & 0.0 & $98.09 \%$ & MF767887.1 \\
\hline
\end{tabular}

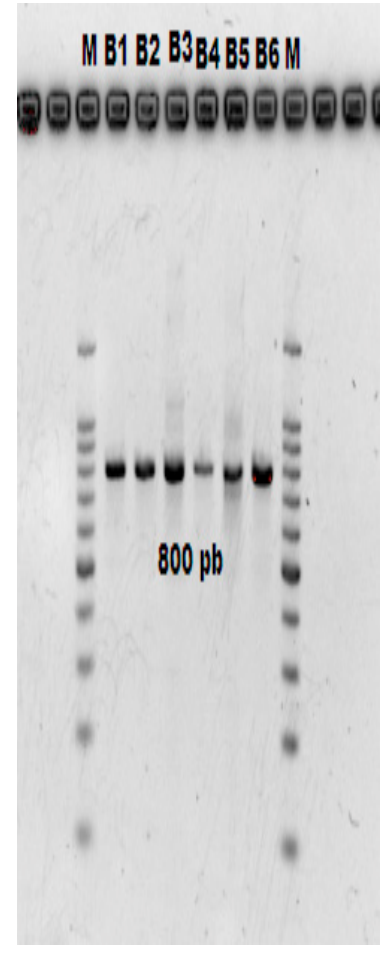

Figura 2. Amplificación del gen $16 \mathrm{~S}$ de las cinco cepas bacterianas. Cada carril corresponde a una bacteria diferente (B1 a B5) y el carril con letra M corresponde al marcador molecular.

Figure 2. Amplification of the $16 \mathrm{~S}$ gene of the five bacterial strains. Each lane corresponds to a different bacterium (B1 to B5), and the lane with the letter $\mathrm{M}$ corresponds to the molecular marker.

suelos (Subhash et al., 2015) y en la rizosfera (Saharan et al., 2011). Especies como Bacillus subtilis, B. megaterium, B. thuringiensis, $B$. cereus y $B$. pumilus, pueden ayudar a mejorar el crecimiento y desarrollo de las plantas a través de la producción de compuestos orgánicos, solubilización de fosfatos y la fijación biológica de nitrógeno (Meena et al., 2016). La identificación de Bacillus spp. en los diferentes usos de suelo en este trabajo, corroboraron la abundancia de estas bacterias en sistemas agroforestales como lo indican los trabajos de Gao et al. (2019) y Liua et al. (2019), también se corroboró la presencia de estas bacterias en pasto como lo había indicado Jorquera et al. (2011).

Sin embargo, a diferencia de los resultados de este trabajo, existen reportes previos de bacterias del género Bacillus en suelos con caña de azúcar (Singh y Kumari, 2016;
Chandra et al., 2018). Por otra parte, nuestros resultados sobre los suelos con vegetación natural coinciden con lo reportado por Uribe et al. (2003) y Ruiz-Sánchez et al. (2015) quienes reportaron la presencia de Bacillus subtilis y $B$. thuringiensis como microorganismos abundantes en áreas de vegetación natural y bosques tropicales.

\section{Evaluación de bacterias en la promoción de crecimiento de chile habanero}

Las semillas de chile habanero inoculadas con las bacterias promotoras del crecimiento vegetal registraron valores entre el 80 y $98 \%$ de emergencia, en contraste con el testigo que únicamente alcanzó el 76\% (Tabla 2). Los mayores porcentajes de emergencia lo obtuvieron las semillas inoculadas con las bacterias VVM1 y JVN5 (Tabla 2), las cuales de acuerdo al análisis estadístico de Friedman fueron significativamente diferentes $\left(T^{2}=6.29, p=0.0001\right)$ a las semillas inoculadas con las bacterias FDMC4, EAV2 y el testigo (Tabla 2).

Los resultados de emergencia variaron en relación a

Tabla 2. Emergencia de plántulas de chile habanero inoculadas con cepas de Bacillus provenientes de suelos con diferentes usos.

Table 2. Emergence of habanero pepper seedlings inoculated with Bacillus strains from soils with different uses.

\begin{tabular}{cccc}
\hline Cepas & Emergencia (\%) & Suma (rangos) & Media (rangos) \\
\hline VVM1 & 98 & 379.50 & $3.80^{\mathrm{a}}$ \\
\hline EAV2 & 80 & 328.50 & $3.29^{\mathrm{de}}$ \\
\hline JAG3 & 86 & 349.50 & $3.50^{\mathrm{bcde}}$ \\
\hline FDMC4 & 83 & 340.50 & $3.41^{\mathrm{cde}}$ \\
\hline JVN5 & 95 & 376.50 & $3.77^{\mathrm{ab}}$ \\
\hline Sin inóculo & 76 & 325.50 & $3.26^{\mathrm{e}}$ \\
\hline
\end{tabular}

Literales diferentes indican diferencias estadísticas $(p<0.05)$ entre tratamientos. Prueba de Friedman, DMS $=28.7$.

los efectos de las bacterias, sólo dos cepas (VVM1 y JVN5) tuvieron un efecto significativo a diferencia de las otras bacterias, las cuales fueron estadísticamente iguales al testigo, lo cual corrobora que algunas cepas de Bacillus disminuyen o no tienen un efecto estimulante en la germinación de chile habanero como lo reporta Sosa-Pech et al. (2019) al obtener una menor germinación en aislados de Bacillus CBCC57 y CBFRF5 en relación al testigo.

Estas variaciones del efecto de cepas Bacillus en la emergencia se han reportado para pimiento, donde se indica que la aplicación de Bacillus sp. MA06 aumentó el porcentaje de emergencia en un $8.0 \%$, pero tres cepas de Bacillus no mostraron diferencia significativa con relación a las semillas sin inocular (Luna et al., 2013). Por otro lado, Díaz-Vargas et al. (2001) reportaron el efecto de rizobacterias en la emergencia de semillas de lechugas, indicando que el $76.6 \%$ de las cepas incrementaron la emergencia, $10 \%$ no tuvieron efecto y $13.3 \%$ la redujeron.

En nuestro trabajo la cepa VVM1 fue la que promovió mayor porcentaje de emergencia, lo que concuerda con lo reportado por Kaymak et al. (2009), donde indican que $B$. megaterium mejoró el porcentaje y la tasa de germinación en 
semillas de rábano, que es la especie con que se asocia esta cepa (Tabla1).

En cuanto a la altura de las plántulas a los 20 ddi, se presentaron diferencias estadísticas significativas, las semiIlas inoculadas con VVM1 y EAV2 fueron las que alcanzaron la mayor altura ( 6.86 y $6.75 \mathrm{~cm}$, respectivamente), con respecto a las semillas inoculadas con JVN5 y el testigo $(6.34 \mathrm{~cm})$; mientras que en las semillas inoculadas con Bacillus sp. FDMC4 y JAG3 no se observaron diferencias estadísticas significativas con los otros tratamientos (Tabla 3).

Por otra parte, a los 20 ddi las plántulas de los tratamientos con JAG3, FDMC4 y VVM1 registraron mayor peso seco $(0.0439,0.0423$ y $0.0414 \mathrm{~g}$, respectivamente) y fueron estadísticamente superior que las plántulas con JVN5, EAV2 y el testigo $(0.0365,0.0304$ y $0.0297 \mathrm{~g}$, respectivamente) Tabla 3).

Tabla 3. Altura y peso seco de plántulas de chile habanero inoculadas con cepas de Bacillus provenientes de suelos con diferentes usos.

Table 3. Height and dry weight of habanero pepper seedlings inoculated with Bacillus strains from soils with different uses.

\begin{tabular}{lcc}
\hline \multirow{2}{*}{ Cepas } & \multicolumn{2}{c}{ Plántula } \\
\cline { 2 - 3 } & Altura $(\mathbf{c m})$ & Peso seco $(\mathbf{g})$ \\
\hline VVM1 & $6.86^{\mathrm{a}}$ & $0.0414^{\mathrm{a}}$ \\
\hline EAV2 & $6.75^{\mathrm{a}}$ & $0.0304^{\mathrm{c}}$ \\
JAG3 & $6.51^{\mathrm{ab}}$ & $0.0439^{\mathrm{a}}$ \\
FDMC4 & $6.70^{\mathrm{ab}}$ & $0.0423^{\mathrm{a}}$ \\
JVN5 & $6.34^{\mathrm{b}}$ & $0.0365^{\mathrm{b}}$ \\
Sin inóculo & $6.34^{\mathrm{b}}$ & $0.0297^{\mathrm{c}}$ \\
C.V. $(\%)$ & 14.1 & 28.7 \\
E.E. & 0.10 & 0.001 \\
\hline
\end{tabular}

Literales diferentes indican diferencias estadísticas $(p<0.05)$ entre tratamientos.

Para el caso de las plantas en macrotúnel, con sustrato inoculado con JVN5 fueron las que alcanzaron una mayor altura inicial $(4.69 \mathrm{~cm})$ y fueron significativamente diferentes a las plantas inoculadas con EAV2 $(3.06 \mathrm{~cm})$ y el testigo $(2.77$ $\mathrm{cm})$. Las plantas inoculadas con VVM1, FDMC4 y JAG3 no registraron diferencias significativas en altura inicial de planta $(4.06,3.88$ y $3.38 \mathrm{~cm}$, respectivamente) en relación a los otros tratamientos (Tabla 4).

En lo que respecta a la altura final de las plantas inoculadas con EAV2 $(38.63 \mathrm{~cm})$, presentaron diferencias estadísticas significativas, con respecto a las plantas inoculadas con FDMC4, B. VVM1 y el testigo $(27.88,27.38$ y $26.83 \mathrm{~cm}$, respectivamente). Por otra parte, las plantas inoculadas con JVN5 y JAG3 no presentaron diferencias significativas con el testigo en relación a la altura final de la planta.

En relación al peso de frutos, en la Tabla 4 podemos observar que las plantas inoculadas con EAV2 $(6.45 \mathrm{~g})$ tuvieron el mayor peso de frutos y fueron significativamente diferentes a las plantas con FDMC4, JVN5 y el testigo (3.96, 3.66 y $2.20 \mathrm{~g}$, respectivamente). También podemos observar en la Tabla 4, que las plantas con JAG3 (5.74 g) y VVM1 (5.61 g) fueron significativamente diferentes al testigo, pero no a los otros tratamientos con bacterias.
Tabla 4. Efecto de cepas de Bacillus en la altura inicial y final de plantas y peso de fruto de chile habanero.

Table 4. Effect of Bacillus strains on the initial and final height of plants, and fruit weight of habanero pepper.

\begin{tabular}{llcc}
\hline \multirow{2}{*}{ Cepas } & \multicolumn{2}{c}{ Altura de planta $(\mathbf{c m})$} & Peso de fruto \\
\cline { 2 - 3 } & \multicolumn{1}{l}{ Inicial } & Final & $(\mathbf{g})$ \\
\hline VVM1 & $4.06^{\mathrm{ab}}$ & $27.38^{\mathrm{c}}$ & $5.61^{\mathrm{ab}}$ \\
\hline EAV2 & $3.06^{\mathrm{b}}$ & $38.63^{\mathrm{a}}$ & $6.45^{\mathrm{a}}$ \\
\hline JAG3 & $3.38^{\mathrm{ab}}$ & $35.63^{\mathrm{ab}}$ & $5.74^{\mathrm{ab}}$ \\
\hline FDMC4 & $3.88^{\mathrm{ab}}$ & $27.88^{\mathrm{bc}}$ & $3.96^{\mathrm{bc}}$ \\
\hline JVN5 & $4.69^{\mathrm{a}}$ & $35.75^{\mathrm{ab}}$ & $3.66^{\mathrm{bc}}$ \\
\hline Sin inóculo & $2.77^{\mathrm{b}}$ & $26.83^{\mathrm{c}}$ & $2.20^{\mathrm{c}}$ \\
\hline C.V. (\%) & 29.6 & 17.5 & 35.7 \\
\hline E.E. & 0.37 & 1.96 & 0.56 \\
\hline
\end{tabular}

Literales diferentes indican diferencias estadísticas $(p<0.05)$ entre tratamientos.

Los resultados obtenidos permiten inferir que las cepas de Bacillus en este trabajo fueron capaces de promover alguna de las siguientes variables en chile habanero, altura de plántula, peso seco de plántula, altura inicial y final de planta y peso de fruto, en comparación al testigo. Sin embargo, destacaron por sus efectos las cepas VVM1, EAV2 y JVN5. Lo anterior pudo ser debido a que algunas bacterias del género Bacillus inducen diferentes mecanismos relacionados con la promoción de crecimiento en las plantas de chile, resultando una expresión diferente en las plantas (GuillénCruz et al., 2006), por lo cual surge la importante necesidad de identificar a nivel especie estas cepas mediante filogenias multilocus.

Al respecto, Sosa-Pech et al. (2019) han reportado que aislados del género Bacillus promueven el crecimiento a nivel de plántula de chile habanero, entre sus tratamientos, los aislados CBCC57 y CBRF12 promovieron el crecimiento en altura de planta y área foliar. En contraste a nuestros resultados sobre que $B$. subtilis no tuvo efecto en el crecimiento de las plantas, pero si en el peso seco, Kokalis-Burelle et al. (2002) encontró que la formulación LS256 (Bacillus subtilis GBO3 y B. pumilis INR7) promovió el crecimiento del tallo, raíz y parte aérea en plántulas de chile.

En relación a $B$. megaterium inoculadas a plantas de tomate, se ha reportado que mejoran significativamente el grosor del tallo, número de ramas, área foliar, contenido de pigmentos fotosintéticos, contenido mineral, contenido total de azúcares, carbohidratos y proteína cruda en las hojas, así como el amarre de frutos, la producción temprana y total de frutos (El-Yazeid y Abou-Aly, 2011). Por otro lado, Surette et al. (2003) aislaron B. megaterium de cultivos de zanahoria, el cual mostró efectos positivos en el crecimiento de la planta.

\section{CONCLUSIONES}

De acuerdo con los resultados obtenidos las cepas VVM1, EAV2 y JVN5 son bacterias que promueven la emergencia, altura y peso seco de plántulas, así como la altura de la planta y peso de fruto de chile habanero, por lo que 
la inoculación con estas cepas mejora el desarrollo de las plántulas, plantas y frutos de chile habanero; sin embargo, se requieren estudios de validación de las cepas a nivel de producción, en condiciones protegidas y de cielo abierto para evaluar el efecto en el desarrollo y producción de chile habanero en condiciones comerciales.

Este estudio constituye un aporte al conocimiento científico sobre la diversidad que existe entre cepas de Bacillus provenientes de diferentes usos de suelo, así como su potencial aplicación como bacterias promotoras de crecimiento vegetal.

\section{AGRADECIMIENTOS}

Al Tecnológico Nacional de México por el financiamiento de los proyectos 6218.19-P y 10544.21-P. Al Consejo Veracruzano de Investigación Científica y Desarrollo Tecnológico por financiar el proyecto 142252.

\section{LITERATURA CITADA}

Arenas-Julio, Y.R., Escalante-Estrada, J.A.S., Aguilar-Carpio, C., Rodriguez-Gonzalez, M.T. y Sosa-Montes, E. 2021. Rentabilidad y rendimiento de girasol en función del tipo de suelo, nitrógeno y biofertilizante. Biotecnia. 23(1): 45-51.

Benbi, D.K. 2013. Greenhouse Gas Emissions from Agricultural Soils: Sources and Mitigation Potential. Journal of Crop Improvement. 27(6): 752-72.

Chandra, P., Tripathi, P. y Chandra, A. 2018. Isolation and molecular characterization of plant growth-promoting Bacillus spp. and their impact on sugarcane (Saccharum spp. hybrids) growth and tolerance towards drought stress. Acta Physiologiae Plantarum. 40, 199: 1-15.

Corrales, R.L.C., Caycedo, L.L., Gómez, M.M.A., Ramos, R.S.J. y Rodríguez, T.J.N. 2017. Bacillus spp: una alternativa para la promoción vegetal por dos caminos enzimáticos. NOVA. 15 (27): 45-65.

Díaz-Vargas, P., Ferrera-Cerrato, R., Almaraz-Suárez, J.J. y AlcantarGonzalez, G. 2001. Inoculación de bacterias promotoras de crecimiento en lechuga. Terra Latinoamericana 19: 327-335.

El-Yazeid, A.A. y Abou-Aly, H.E. 2011. Enhancing growth, productivity and quality of tomato plants using phosphate solubilizing microorganisms. Australian Journal of Basic and Applied Sciences. 5: 371-379.

Espinosa-Palomeque, B., Cano-Ríos, P. Salas-Pérez, L., GarcíaHernández, J.L., Preciado-Rangel1, P., Sáenz-Mata, J. y ReyesCarrillo, J. L. 2019. Bioinoculantes y concentración de la solución nutritiva sobre la producción y calidad de tomate. Biotecnia. 21(3): 100-107.

Franco, A.L.C., Bartz, M.L.C., Cherubin, M.R., Baretta, D., Cerri, C.E.P., Feigl, B.J., Wall, H.D., Davies, A.C. y Cerri, C.C. 2016. Loss of soil (macro) fauna due to the expansion of Brazilian sugarcane acreage. Science of the Total Environment. 563564: 160-168.

Gao, P., Zheng, X., Wang, L., Liu, B. y Zhang, S. 2019. Changes in the Soil Bacterial Community in a Chronosequence of Temperate Walnut-Based Intercropping Systems. Forests. 10, 299: 1-14.

Giraffa, G., Rossetti, L. y Neviani, E. 2000. An evaluation of chelexbased DNA purification protocols for the typing of lactic acid bacteria. Journal of Microbiological Methods. 42: 175-184.
Grageda-Cabrera, O.A., Díaz-Franco, A., Peña-Cabriales, J.J. y Vera-Nuñez, J.A. 2012. Impacto de los biofertilizantes en la agricultura. Revista Mexicana de Ciencias Agrícolas. 3(6):1261-1274.

Guillén-Cruz, R., Hernández-Castillo, F.D., Gallegos- Morales, G., Rodríguez-Herrera, R., Aguilar-González, C.N., Padrón-Corral, E. y Reyes-Valdés, M.H. 2006. Bacillus spp. como Biocontrol en un Suelo Infestado con Fusarium spp., Rhizoctonia solani Kühn y Phytophthora capsici Leonian y su Efecto en el Desarrollo y Rendimiento del Cultivo de Chile (Capsicum annuum L.). Revista Mexicana de Fitopatología. 24(2): 105114.

Jorquera, M.A., Crowley, D.E., Marschner, P., Greiner, R., Fernández, M.T., Romero, D., Menezes-Blackburn, D. y Mora, M. de la L. 2011. Identication of B-propeller phytaseencoding genes in culturable Paenibacillus and Bacillus spp. from the rhizosphere of pasture plants on volcanic soils. FEMS Microbiology Ecology. 75:163-172.

Kaur, B., Gupta, S., y Singh, G. 2002. Bioamelioration of a sodic soil by silvopastoral systems in northwestern India. Agroforestry Systems. 54: 13-20.

Kaymak, H.C., Guvenc, I., Yarali, F. y Donmez, M.F. 2009. The effects of bio-priming with PGPR on germination of radish (Raphanus sativus L.) seeds under saline conditions. Turkish Journal of Agriculture and Forestry. 33(2):173-179.

Kokalis-Burelle, K., Vavrina, C.S., Rosskopf, E.N. y Shelby, R.A. 2002. Field evaluation of plant growth-promoting Rhizobacteria amended transplant mixes and soil solarization for tomato and pepper production in Florida. Plant and Soil. 238: 257266.

Liua, C., Jina, Y., Hub, Y., Tanga, J., Xiongc, Q., Xud, M., Bibia, F. y Benge, K.C. 2019. Drivers of soil bacterial community structure and diversity in tropical agroforestry systems. Agriculture, Ecosystems and Environment. 278: 24-34.

Luna, M.R.A., Reyes, P.J.J., Espinosa, C.K.A., Luna, M.M.V., Luna, Q.F.V., Celi, M.M.V., Espinoza, C.A.L., Rivero, H.M., Cabrera, B.D.A., Alvarado, M.A.F. y González, R.J.C. 2016. Efecto de diferentes abonos orgánicos en la producción de tomate (Solanum lycopersicum, L). Biotecnia. 18(3): 33-36.

Luna, M.L., Martínez, P.R.A., Hernández, I.M., Arvizu, M.S.M. y Pacheco, A.J.R. 2013. Caracterización de rizobacterias aisladas de tomate y su efecto en el crecimiento de tomate y pimiento. Revista Fitotecnia Mexicana 36: 63-69.

Mantilla-Paredes, A.J., Cardona, G.I., Peña-Venegas, C.P., Murcia, U., Rodríguez, M., Zambrano, M.M. 2009. Distribución de bacterias potencialmente fijadoras de nitrógeno y su relación con parámetros fisicoquímicos en suelos con tres coberturas vegetales en el sur de la Amazonia colombiana. Revista de Biología Tropical. 57(4): 915-927.

Meena, V.S., Maurya, B.R., Meena, S.K., Meena, R.K., Kumar, A., Verma, J.P. y Singh, N.P. 2016. Can Bacillus Species Enhance Nutrient Availability in Agricultural Soils?. En: M. Islam, M. Rahman, P. Pandey, C. Jha y A. Aeron (eds.), pp 367-395. Bacilli and Agrobiotechnology. Springer, Cham.

Mendivil-Lugo, C., Nava-Pérez, E., Armenta-Bojórquez, A.D., Ruelas-Ayala R.D., Félix-Herrán, J.A. 2020. Elaboración de un abono orgánico tipo bocashi y su evaluación en la germinación y crecimiento del rábano. Biotecnia. 22(1): 1723.

Murillo-Cuevas, F.D., Adame-García, J., Cabrera-Mireles, H. y Fernández-Viveros, J.A. 2019. Fauna y microflora edáfica 
asociada a diferentes usos de suelo. Ecosistemas y Recursos Agropecuarios. 6 (16): 23-33.

Paudel, B.R., Udawatta, R.P., Kremer, J.R., y Anderson, S.H. 2012. Soil quality indicator responses to row crop, grazed pasture, and agroforestry buffer management. Agroforestry Systems. 84: 311-323.

Ramírez-Vargas, B. A., Carrillo-Ávila, E., Obrador-Olán, J. J., CohMéndez, D., Monsalvo-Espinosa, A., y Aceves-Navarro, E. 2019. Aplicación del modelo simplificado para estimar dosis sustentables de fertilización fosforada en el cultivo de chile habanero (Capsicum chinense Jacq.). Investigación y Ciencia de la Universidad Autónoma de Aguascalientes. 27(78): 2333.

Reyes, G. y D. Cortéz. 2017. Intensidad en el uso de fertilizantes en América Latina y el Caribe (2006-2012). Bioagro. 29 (1): 45-52.

Reyes-Pérez, J.J., Luna-Murillo, R.A., Zambrano-Burgos, D., Vázquez-Morán, V.F., Rodríguez-Pedroso, A.T., RamírezArrebato, M.Á., Guzmán-Acurio, J.A., González- Rodríguez, J.C. y Torres-Rodríguez, J.A. 2018. Efecto de abonos orgánicos en el crecimiento y rendimiento agrícola de la berenjena (Solanum melongena L.). Biotecnia. 20(1): 8-12.

Ríos, R.Y., Dibut, Á.B., Rojas, B.M., Ortega, G.M., Arozarena, D.N. y Rodríguez, S.J. 2016. Interacción de la bacteria Gluconacetobacter diazotrophicus y hortalizas de raíz. Cultivos Tropicales. 37: 28-32.

Rodríguez-Hernández, M.G., Gallegos-Robles, M.Á., RodríguezSifuentes, L., Fortis-Hernández, M., Luna-Ortega, J.G. y González-Salas, U. 2020. Cepas nativas de Bacillus spp. como una alternativa sostenible en el rendimiento de forraje de maíz. Terra Latinoamericana. 38: 313-321.

Ruiz-Bello, R., Nava-Tablada, M.E., Landeros-Sánchez, C. y DíazPadilla, G. 2016. Potencial productivo y limitantes para el cultivo de chile habanero (Capsicum chinense Jacq.) en el estado de Veracruz, México. RINDERESU. 1(1): 01-11.

Ruiz-Sánchez, E., Mejía-Bautista, M.Á., Serrato-Díaz, A., ReyesRamírez, A., Estrada-Girón, Y. y Valencia-Botín, A.J. 2016. Antifungal activity and molecular identification of native strains of Bacillus subtilis. Agrociencia. 50:133-148.
Saharan, B.S. y V. Nehra. 2011. Plant growth promoting Rhizobacteria: A critical review. Life Sciences and Medicine Research. 21: 1-30.

Servicio de Información Agroalimentaria y Pesquera SIAP, Blog. [Consultado 11 febrero 2021] 2016. Disponible en: https:// www.gob.mx/siap/articulos/somos-noveno-productor-dehortalizas-a-nivel-mundial

Singh, P. y Kumari, P. 2016. Isolation and characterization of amylase producing Bacillus spp. from selected soil sample. International Journal of Research in Biosciences. 5 (2): 24-29.

Sosa-Pech, M., Ruiz-Sánchez, E., Tun-Suárez, J.M., Pinzón-López, L.L. y Reyes-Ramírez A. 2019. Germinación, crecimiento y producción de glucanasas en Capsicum chinense Jacq. inoculadas con Bacillus spp. Ecosistemas y Recursos Agropecuarios. 6(16):137-143.

Subhash, Y., Rajeev, K., Saxena, A.K. y Arora, D.K. 2015. Diversity and phylogeny of plant growth-promoting bacilli from moderately acidic soil. Journal of Basic Microbiology. 51: 98-106.

Surette, M.A., Sturz, A.V., Lada, R.R. y Nowak, J. 2003. Bacterial endophytes in processing carrots (Daucus carota L. var. sativus): their localization, population density, biodiversity and their effects on plant growth. Plant and Soil. 253(2): 381-390.

Torres, R.J.A., Reyes, P.J.J. y González, R.J.C. 2016. Efecto de un bioestimulante natural sobre algunos parámetros de calidad en plántulas de tomate (Solanum lycopersicum, L.) bajo condiciones de salinidad. Biotecnia. 18(2): 11-15.

Uribe, D., Martinez, W. y Cerón, J. 2003. Distribution and diversity of cry genes in native strains of Bacillus thuringiensis obtained from different ecosystems from Colombia. Journal of Invertebrate Pathology. 82: 119-127.

Vallejo-Quintero, V.E. 2013. Importancia y utilidad de la evaluación de la calidad de suelos mediante el componente microbiano: experiencias en sistemas silvopastoriles. Colombia Forestal. 16(1): 83-99.

Vessey, J.K. 2003. Plant growth promoting rhizobacteria as biofertilizers. Plant and soil 255(2): 571-586. 